\title{
La postura de Estados Unidos sobre el Protocolo de Kyoto y el cambio climático
}

Introducción

$\mathrm{E}$ I nivel de industrialización y el liderazgo mundial de Estados Unidos de América fueron los motivos fundamentales por los que la comunidad internacional condenó, de manera tajante, el rechazo de este país al Protocolo de Kyoto. Resulta irónico e inquietante que la nación con mayor emisión de gases contaminantes y la principal promotora de los bienes públicos mundiales no hubiese ratificado y abanderado el primer Acuerdo internacional que intenta poner freno a los efectos adversos del cambio climático.

Estados Unidos, en su historia reciente, ha sido pionero en el proceso de investigación, inversión e instrumentación de medidas ecológicas en favor de los recursos naturales y el cambio climático; hecho que lo ha llevado a autonombrarse "líder en la protección del medio ambiente" y a comprometerse a ayudar a otras economías a mantener un equilibrio ambiental dentro del interior de sus territorios. ${ }^{1}$ No obstante este papel activo, en 2004, alegando daños a la economía doméstica, dio un no rotundo al Protocolo de Kyoto.

La discordancia que existe en el comportamiento de la nación estadounidense

* Profesora-Investigadora del Departamento de Estudios del Pacífico, cucsH-Universidad de Guadalajara. ORCID http:// orcid.org/0000-0002-4553-8141 ha despertado el interés por analizar qué hay detrás de esta conducta poco ortodoxa en una potencia económica-política que promueve de manera constante e innovadora la protección al medio ambiente y la construcción de regímenes internacionales. En este sentido surgen las siguientes interrogantes: ¿qué hace que un líder mundial decida no intervenir en el primer convenio internacional que intenta revertir las secuelas del cambio climático?, ¿acaso Estados Unidos no es consciente de la vulnerabilidad a la que se expone todo el planeta si no se pone fin a los efectos de este fenómeno ambiental?, ¿por qué predica el bienestar del medio ambiente pero es incapaz de comprometerse ante la comunidad internacional?, ¿qué componentes del Protocolo de Kyoto no convencieron al gobierno de Estados Unidos?, ¿qué elementos de la política doméstica le impidieron a este país ratificar el mencionado Protocolo?

Éstas son algunas de las preguntas que se tratarán de contestar en este trabajo. En primer lugar se expondrá, grosso modo, la historia interrelacionada de Estados Unidos con el Protocolo de Kyoto. Luego se analizará la economía de esa nación, su relación con el medio ambiente y el papel alternativo que tomó la Casa Blanca con respecto al mencionado Protocolo. Y, por último se hablará del papel de Estados Unidos en su lucha contra el cambio climático en la arena internacional. 


\section{Estados Unidos y el Protocolo de Kyoto}

El Protocolo de Kyoto tiene sus orígenes en la Cumbre de la Tierra, celebrada en Río de Janeiro, Brasil, en 1992. En esta ocasión más de 130 países se reunieron en la mesa de negociación para tratar dos temas de gran relevancia: la protección ambiental y el desarrollo económico. Por tal motivo, los estudiosos vislumbraron la Cumbre como el punto crucial en el manejo ambiental global pues, como Hunter y Honey señalan, la conferencia permitiría que tanto los países del Norte como los del Sur caminaran por la misma senda. Por un lado, "el Sur recibió de los países del Norte el compromiso renovado para incrementar la asistencia de desarrollo, (como reconocimiento de que el Norte fue esencialmente responsable de la degradación del medio ambiente global) y, por el otro, el compromiso de que las naciones del Norte tomarían el liderazgo global en los problemas del medio ambiente". ${ }^{2}$

Producto del encuentro se establecieron varios acuerdos, ${ }^{3}$ entre los que sobresale la Convención Marco de Naciones Unidas sobre el Cambio Climático (CMNUCC) ${ }^{4}$ que, junto con el Convenio sobre la Diversidad Biológica, se distingue por su carácter obligatorio. El cometido de la CMNUCC fue que los países industrializados redujeran sus emisiones de gases de efecto invernadero a los niveles de 1990 antes del año 2000. Tal vez fue lo novedoso y relevante del tema, o sólo una estrategia de campaña del entonces presidente de Estados Unidos, George Bush, pero éste firmó el Acuerdo el 12 de junio de 1992 y lo ratificó el 15 de octubre de ese mismo año. Es decir, la postura del país del Norte hacia este Acuerdo evidenciaba disposición e interés.
Conforme avanzó el tiempo, la indiferencia global hacia la CMNUCC fue patente, por tal motivo, en 1996, en la Conferencia de Ginebra se propuso un acuerdo que estableciera resultados definidos (cuantitativos y cualitativos), con plazos concretos y fuerza jurídica obligatoria, mismo que se estableció en Japón en 1997, con el nombre de Protocolo de Kyoto. ${ }^{5}$ La diferencia entre éste y la CMNUCC es que aquí el periodo para disminuir la emisión de gases se recorrió hasta 2008-2012 y que la reducción de contaminantes ya no es a los niveles de 1990 sino que sólo $5.2 \%$ en relación con este año. Es decir, resultó menos ambicioso pero, formalmente, más comprometido.

El 12 de noviembre de 1998, durante el gobierno de Bill Clinton, Estados Unidos, junto con otros países, firmó el Protocolo de Kyoto. Pero, a pesar de la disposición general de los representantes de Estado para poner en marcha este bien público global, no existía un consenso concreto sobre la manera de reducir las emisiones de gases contaminantes pues, evidentemente, poner en práctica el compromiso implicó hacer un diagnóstico costo-beneficio de las medidas que se deberían adoptar, conscientes de que los costos serían nacionales y los beneficios internacionales.

Además de los asuntos económicos, Estados Unidos discutía seriamente la no obligatoriedad de China e India de cumplir con el objetivo, pues sostenía que si bien eran países en vías de desarrollo, su porcentaje de emisión de gases era relativamente alto e iba en aumento. Mientras que las naciones no desarrolladas exigían "equidad en los derechos individuales a los recursos ambientales globales"; 6 es decir, beneficiarse de los recursos naturales y de la capacidad de asimilación de contaminación propia del medio ambiente. Tras esta discusión, los países activos por consenso acordaron 
cumplir con las obligaciones del Protocolo de Kyoto, por medio de los mecanismos flexibles, ${ }^{7}$ que cuales brindan la posibilidad al país signatario de alcanzar la meta por vías alternas a las de sólo tomar medidas en el sector productivo doméstico.

De acuerdo con la seriedad con la que intentaban revestir al Protocolo de Kyoto, se estableció que el compromiso de cumplimiento no sería obligatorio hasta que los países industrializados, responsables de al menos $55 \%$ de las emisiones mundiales, lo ratificaran. Es decir, el Protocolo entraría en vigor hasta contar con un número suficiente de países del anexo $\mathrm{I}^{8}$ que hubiesen sido y continuaran siendo los principales beneficiados de la quema de combustibles fósiles que requiere el proceso de industrialización. ${ }^{9}$ Pese a que Estados Unidos contribuye con casi una cuarta parte de los gases de efecto invernadero, en 2001 el gobierno de George W. Bush se retiró del Protocolo, por considerarlo imperfecto y dañino para la economía doméstica, al poner en peligro el crecimiento económico y la competitividad de su comercio. ${ }^{10}$

Tanto los Organismos no Gubernamentales (ONG), como representantes de los países ante el sistema internacional, instaban a Estados Unidos a reconsiderar su postura. ${ }^{11}$ Durante más de tres años sostuvieron la importancia de contar con el compromiso y el liderazgo de Washington en este proyecto. El desinterés de la Casa Blanca en la ratificación del Acuerdo del Protocolo desalentó al resto de los gobiernos a concretarlo, motivo por el que no lograban convencer a las economías industrializadas que faltaban. Finalmente, en 2004, la adhesión de Rusia hizo posible el despunte del Protocolo de Kyoto, que entró en vigor el 16 de febrero de 2005. Al respecto, el vocero de la Casa Blanca anunció haber "elegido un camino diferente al del
Protocolo de Kyoto, que garantiza, por un lado, no dañar la economía estadounidense $y$, por el otro, ser aceptado por todos los países del mundo". ${ }^{12}$

Hasta aquí resaltan tres cosas: 1. Estados Unidos desertó del Protocolo de Kyoto argumentando daños a su economía, 2. En 2004 afirmó contar con mecanismos propios para frenar el cambio climático sin causar estragos económicos internos, y 3. Aparentemente a la Unión Americana le interesa conservar la buena imagen ante la comunidad internacional. En este sentido, surgen las siguientes dudas, ¿cuáles son los fundamentos en los que se basa Estados Unidos para alegar perjuicios a la economía doméstica?, y ¿cuál es la postura de este país frente el cambio climático en el sistema internacional? En el siguiente apartado se tratará de responder a estos cuestionamientos.

\section{La economía de Estados Unidos, su relación con el medio ambiente y el papel alternativo al Protocolo de Kyoto}

Cuando se intenta analizar la economía ambiental doméstica de una nación cualquiera se deben examinar tres aspectos relevantes: la relación que existe entre la economía y el medio ambiente, el tipo de sistema económico del país y la postura del gobierno en el asunto. Así, mediante este estudio general, se podrá entender la posición de un país frente a un acuerdo internacional en favor de la protección ambiental mundial.

Estados Unidos mantiene una economía capitalista avanzada que se caracteriza por manejar

una compleja red de comercio, entre los individuos y entre los países, que depende de un elevado grado de especialización y de una intrin-

MÉXICO YLACUENCADEL PACÍFICO

vol. 10, núm. 28 / enero - abril de 2007

63 
cada división de trabajo... así como de dinero y de las tecnologías industriales modernas que se basan en la utilización de enormes cantidades de capital"13

y en la que, a través de la globalización, se garantiza el aumento de la producción interna y la creciente tasa de intercambios comerciales con el mundo.

Según la perspectiva neoclásica, la economía depende por completo del medio ambiente natural: $a$ ) de la extracción de los recursos no renovables y la cosecha de los elementos renovables; usados como medio y factores de la producción; $b$ ) por su carácter de depósito y asimilación de los contaminantes y c) como medio de recreación. ${ }^{14}$ Esto nos da elementos para presentar las tres observaciones siguientes: 1 . El medio ambiente es la base de la economía y de la vida, 2. El sistema capitalista genera desperdicios que van a parar directamente en el medio ambiente y 3 . Los recursos naturales son finitos. Por tanto, aun cuando la naturaleza provee "la materia prima y la energía que hacen posible la producción y el consumo", ${ }^{15}$ existen límites tanto para extraer la materia del medio ambiente como para contaminar, pues el agotamiento de los recursos y de la capacidad de asimilación de la tierra ponen en peligro el sistema socio-económico actual, junto con la vida misma. En otras palabras, el sistema capitalista se sostiene gracias a la producción y el consumo, que se basan en la utilización de combustibles fósiles y de productos de la naturaleza, y que después del proceso de industrialización regresan al medio ambiente como productos finales (que tarde o temprano se convierten en basura) o residuos (gráfica 1 ).

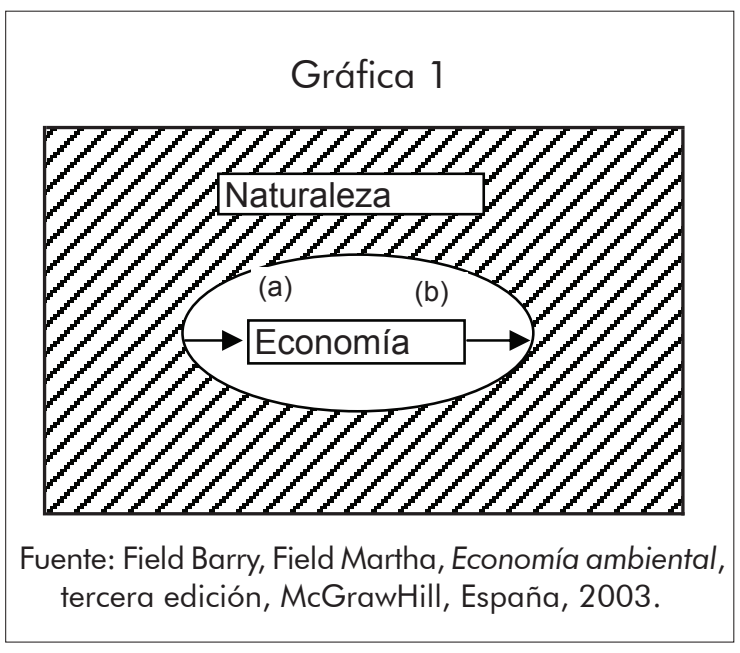

En la gráfica 1 podemos ver que la flecha (a) indica el flujo de materias primas hacia la producción y el consumo; mientras que la flecha (b) muestra las repercusiones de la actividad económica sobre la calidad del entorno. ${ }^{16}$ Haciendo un análisis simple, esta estrecha relación lleva a reflexionar que el cuidado del medio ambiente implica disminuir el ritmo de crecimiento económico de un país y, a su vez, promover el desarrollo económico involucra daños en la naturaleza. El equilibrio óptimo entre producción y cuidado ambiental es un asunto que no se tocará en este trabajo.

Para justificar su no adhesión al Protocolo de Kyoto el gobierno de Estados Unidos alegó daños en su economía interna, tales como aumento de desempleo, cierre de fábricas y pérdida de competitividad en el mercado internacional; pese a que este país es el principal emisor de dióxido de carbono en el mundo. No obstante, en el caso específico de Estados Unidos, Barry y Martha Field aseguran que no existe una relación definitoria entre protección ambiental y los perjuicios a la 
economía. ${ }^{17}$ Argumentan para ello que, por un lado, en 1990 el costo por los gastos del control de la contaminación de la industria manufacturera, en promedio, sólo ascendió a $1.72 \%$, relativamente poco como para ser la causa de despidos en masa (dato respaldado por los datos del Departamento de Trabajo de Estados Unidos, que indicó que en el periodo de 1987-1990 los despidos que se atribuyen a la normatividad ambiental sólo representaron uno \% del total). Mientras que para su funcionamiento, la industria del control de la contaminación cada vez hace "un uso más intensivo de mano de obra de este factor que el resto de la economía". ${ }^{18}$ Lo que implica, según los autores, un beneficio más a la población económicamente activa que un perjuicio.

Por otro lado, Field y Field aseguran que no se afecta la competitividad industrial estadounidense en el mercado internacional, porque el incremento de $1.72 \%$ a los costos no es una cifra muy elevada, especialmente si se considera que los principales socios comerciales de este país también tienen prácticas y regulaciones medioambientales similares a las de su economía. ${ }^{19}$

Hasta aquí tenemos dos posturas que pueden o no justificar y hacer comprensible la posición de Estados Unidos frente al Protocolo de Kyoto: a) La escuela neoclásica que explica la relación de la economía con el medio ambiente, en la que reducir las emisiones de dióxido de carbono implica producir menos o instrumentar medidas (tecnológicas) en la industria que de cualquier manera generan costos, y $b$ ) la perspectiva de Field y Field, que argumentan la no relación directa entre protección ambiental y los daños a la economía.

Por el lado político, en Estados Unidos el método analítico para evaluar los programas públicos es el análisis costo-beneficio.
En 1981, el entonces presidente de Estados Unidos, Ronald Reagan, estableció una orden ejecutiva en la que indicaba que "toda regulación pública de importancia debería someterse a un análisis costo-beneficio"; ${ }^{20}$ que se renovó en el periodo de gobierno de Bill Clinton y que en la actualidad continúa vigente. En la toma de decisiones acerca del medio ambiente, la política que se aplica para evaluar un programa no es la excepción y se le conoce como análisis de impacto regulatorio.

Conociendo el criterio y la seriedad del asunto, lo más probable es que la entrada al Protocolo de Kyoto se haya evaluado con el enfoque costo-beneficio. Desde esta perspectiva, lo que se puso en la balanza fueron los costos nacionales contra los beneficios internacionales. Como se dijo al principio, finalmente Estados Unidos se abstuvo de participar en el Protocolo; pero, al menos de manera formal, esta nación ha tomado medidas, tanto dentro como fuera de su territorio, en relación con el cambio climático. Según Tuttle y Andrasko, el gobierno estadounidense se decidió por un enfoque tecnológico basado en proyectos. La práctica política se concentra en tres puntos: ${ }^{21}$

1. Programas voluntarios de reducción y registro de gases de invernadero, que llevan la cuenta de las reducciones de emisiones por las compañías y otras entidades.

2. Investigaciones sobre tecnologías avanzadas en el sector de la energía y otros para reducir las emisiones y elevar la absorción (geológica y terrestre) de carbono.

3. Iniciativas sectoriales de compromisos voluntarios para reducir las emisiones en todo un sector (por ejemplo, los sectores del aluminio y los productos forestales). ${ }^{22}$

MÉXICO YLACUENCADEL PACÍFICO vol. 10, núm. 28 / enero - abril de 2007 
Por lo anterior, se establece que Estados Unidos no ha abandonado completamente el compromiso social de contribuir con la disminución de los gases de efecto invernadero, pues los esfuerzos para mitigar el cambio climático existen. Incluso a mediados de 2005 este país fundó junto con Australia (otra de las economías desertoras del Protocolo), la Asociación Asia-Pacífico sobre Desarrollo Limpio y Cambio Climático (AP6), ${ }^{23}$ tratado internacional alternativo al Protocolo.

La propuesta de la AP6 se presenta un tanto novedosa en el sentido de que es el sector privado, y no el gobierno, quien asume la responsabilidad de la lucha contra la emisión de gases de efecto invernadero, y que para lograrlo se promueve la utilización de tecnología no contaminante, en vez de la reducción de la producción. Mientras que los gobiernos sólo son facilitadores del trabajo de los industriales. Al mismo tiempo, se acordó la utilización de energías renovables, de energía nuclear y el almacenamiento de carbono y metano. ${ }^{24}$

En suma, independientemente de las posturas de los daños o no a la economía doméstica, es evidente que Estados Unidos no puede dejar de lado - sea por la presión de los ciudadanos, ONG, observadores internacionales o por convicción misma de la administración - el compromiso de la disminución de los gases de efecto invernadero, aunque evidentemente su propuesta a simple vista resulta menos riesgosa y costosa.

Económicamente se puede entender la postura de protección dentro del sector productivo estadounidense, pero ¿qué hace que Estados Unidos, por lado, rechace liderar el primer acuerdo internacional que pretende revertir los efectos del cambio climático y, por otro, cree una alianza alternativa al Protocolo de Kyoto?, ¿por qué en el análisis costo-beneficio la participación internacional fue importante?

\section{Estados Unidos y su lucha contra el cambio climático en la arena internacional}

Se debe iniciar este apartado destacando que en los años recientes el tema de la protección ambiental ha sido uno de los principales desafíos de las relaciones internacionales y que en este asunto Estados Unidos no es un país más, sino que se trata de la principal potencia mundial, la primera emisora de gases de efecto invernadero en el planeta y uno de los mayores consumidores de recursos naturales del mundo..$^{25}$ Y que, además, existe incertidumbre en la estructura del sistema internacional en la llamada era de la información.

Para realizar este análisis se propone partir de las afirmaciones de Mearsheimer, quien sostiene que los Estados siempre buscan maximizar su poder y preservar la hegemonía. ${ }^{26}$ Estos dos conceptos (poder y hegemonía) son importantes para este trabajo porque en la era actual (inicios del siglo xxI, donde se ha dejado de lado la Guerra Fría) existe una serie de incertidumbres que lleva a los Estados a estar más alertas al tomar las decisiones primordiales, entre ellas los acuerdos para preservar el medio ambiente con el fin de mantener o mejorar su posición en la arena internacional.

Para algunos autores como Wohlforth, la estructura internacional es unipolar y pacífica, determinando a Estados Unidos como la única súper potencia mundial, ${ }^{27}$ mientras que para Mearsheimer la estructura es multipolar y con posibilidades de ser más violenta que en la era bipolar. ${ }^{28}$ En este sentido, lo que más conviene a Estados Unidos es mantenerse como potencia líder, independientemente de los 
dos escenarios que se presentan. Tener la capacidad de influir en los otros Estados a conveniencia de los intereses de la nación estadounidense mediante el soft power, ${ }^{29}$ el hard power ${ }^{30}$ o ambos, es garantía de supremacía y liderazgo.

Mearsheimer sustenta la búsqueda de poder y hegemonía por parte de los Estados con cinco supuestos: a) el sistema internacional es anárquico, $b$ ) las grandes potencias poseen arsenal militar, c) los Estados nunca están seguros de las intenciones de otros Estados, $d$ ) la sobrevivencia es la meta principal de las grandes potencias, e) las grandes potencias son actores racionales. ${ }^{31}$ Resulta interesante observar que, excepto el inciso $b$ ), con estos puntos podemos analizar la postura de Estados Unidos en el Protocolo de Kyoto. Veremos por qué.

Si en el sistema internacional existen Estados independientes sin autoridad central supranacional, entonces a Estados Unidos le conviene tener habilidad e influencia para dominar las reglas y los acuerdos que rigen la economía y la política internacional. Así pues, no se entiende la postura de Estados Unidos de no liderar el Protocolo de Kyoto, pero regresaremos más tarde a este punto.

Si los Estados nunca pueden estar seguros de las intenciones de otros Estados, entonces es posible que, considerando que disminuir la emisión de gases de efecto invernadero es un bien público mundial, Estados Unidos desconfía de los acuerdos hechos por los otros países, es decir, es consciente de que no existe certeza total de que se realice el compromiso de cooperación, pues los países tienden a comportarse como free rider en los bienes públicos mundiales. Además, no se tiene la seguridad de que el resto de los países del anexo I hagan los reajustes necesarios en el sistema productivo interno para alcanzar el objetivo, lo que indudablemente llevaría a Estados Unidos a tener desventaja competitiva con respecto a los demás. En este mismo punto cabe recordar que China e India podrían olvidar su compromiso moral — no obligatorio- de reducir sus emisiones, trayéndoles ventajas en el comercio mundial en su relación con Estados Unidos.

Si la sobrevivencia es la meta principal de las grandes potencias, entonces en el análisis costo-beneficio de la entrada al Protocolo de Kyoto, Estados Unidos no quiere correr el riesgo en su economía doméstica y prefiere mantener su ritmo de crecimiento económico ascendente, como medio de protección de su población.

Si consideramos que los Estados son actores racionales, entonces es de esperar que Estados Unidos analice el medio ambiente externo y el interno, observe cómo las preferencias de los otros Estados podrían afectar su propia conducta y viceversa, y cómo su propia estrategia afectaría la conducta de los demás países. ${ }^{32}$ Así, en el contexto del rechazo al Protocolo de Kyoto, la Casa Blanca sabe que lo más factible es que los países signatarios de éste persigan el fin con desaliento y pocos bríos. Al mismo tiempo, la Unión Americana es consciente de que su decisión es condenada por la comunidad internacional, hecho que de ninguna manera le conviene, pues le resta prestigio y credibilidad a los valores estadounidenses. Es decir, a la hegemonía lograda, en buena parte, mediante el soft power. Esto último se enlaza con el primer inciso (la anarquía del sistema internacional) por el desconcierto causado porque que Estados Unidos dejó la oportunidad de abanderar el Protocolo de Kyoto, pues ratificar el acuerdo era una manera de consolidar y mantener su hegemonía (por la importancia del medio ambiente). Por 
ello resulta interesante tratar de explicar las causas de este resultado.

Como se señaló al principio de este apartado, hay incertidumbre en el orden internacional actual (la era de la información). Al respecto, Nye desarrolla un análisis sugestivo que puede justificar o responder a las interrogantes sobre la conducta de Estados Unidos. En primer lugar señala que en la era de la información, el soft power tiene mayor relevancia que en épocas anteriores, por tanto, los otros Estados tienden a seguir el liderazgo de un país en particular cuando existe afinidad o empatía con sus valores y cuando no se es demasiado arrogante; de tal forma que "los valores son fuente significante de soft power". ${ }^{33}$ Segundo, la razón por la que los intereses de Estados Unidos van más allá de su frontera se debe, por un lado, a que existen eventos externos que pueden perjudicar al país y, por el otro, a que le interesa influir en la toma de decisiones de los gobiernos y las organizaciones en diversos temas, como la proliferación de armas, el terrorismo, las drogas, los daños ecológicos, entre otros. Desde esta perspectiva, conviene cooperar en la formación de bienes públicos mundiales, como el Protocolo de Kyoto. De lo contrario, "cuando una potencia del tamaño de Estados Unidos le da mayor atención a los intereses domésticos antes que a las necesidades globales, el respeto se puede volver molestia y desprecio". ${ }^{34} \mathrm{Y}$ agrega: "la gran estrategia primeramente debe asegurar la sobrevivencia, pero luego ésta se debe enfocar en la provisión de bienes públicos globales", ${ }^{35}$ así, asegura Nye, se gana dos veces: "de los bienes públicos y de la manera en que ellos legitiman el poder de los Estados Unidos ante los ojos de los otros". ${ }^{36}$

Como se aprecia, liderar un acuerdo internacional de la magnitud del Protocolo de Kyoto representa prestigio y reconocimiento (valores de soft power) para las grandes potencias, que les permiten consolidar el poder y la hegemonía de un país grande. Sin embargo, aun cuando las cosas se empiezan a aclarar no se ha contestado cabalmente por qué Estados Unidos rechazó el Protocolo de Kyoto. Al respecto de esta última inquietud, la discusión de Nye sobre la postura unilateral o multilateral que debe adoptar Estados Unidos en esta era de la información nos puede ayudar a concluirlo.

En congruencia con que en la era de la información el soft power adquiere mayor relevancia que en ningún otro periodo, Nye se inclina por uso del multilateralismo en la política exterior de Estados Unidos antes que el unilateralismo, tanto en los problemas globales en los que este país no puede dar solución solo, como por la conveniencia de tener aliados. ${ }^{37}$ Empero, señala siete pruebas para considerar una u otra postura:

1) En caso de que involucre los intereses vitales, no se deberían dejar fuera las acciones unilaterales, aunque, cuando sea posible se debe buscar el apoyo internacional para esas acciones. 2) Se debe ser precavido en los acuerdos multilaterales que interfieran con la habilidad para producir la paz en áreas volátiles. 3) Algunas veces las tácticas unilaterales ayudan a estimular a otros a comprometerse para que avancen los intereses multilaterales. 4) Estados Unidos debe rechazar las iniciativas multilateralistas que sean recetas para la inacción, que promuevan otros intereses o que sean contrarios a los valores estadounidenses. 5) El multilateralismo es esencial o intrínseco para temas de cooperación que no puedan ser manejados por Estados Unidos sin la ayuda de otros. 6) El multilateralismo debe ser visto como un medio de compartir la carga con otros y comprar la idea de la provisión de bienes públicos. 7) En la elección de las tácticas multilaterales o unilaterales, se deben considerar los efectos de las decisiones sobre el soft power. Si se continúa definiendo el poder en términos militares se está fallando en entender las necesidades 
de invertir en otros instrumentos [...] el soft power está incrementando su importancia, pero es frágil y puede ser destruido por el excesivo unilateralismo y por la arrogancia. ${ }^{38}$

Desde el punto de vista de la Casa Blanca, la aplicación del Protocolo de Kyoto resultaría dañina a los intereses de Estados Unidos, entonces se estaría pensando que los mandatarios basaron su decisión en los puntos 1 y 4 . Mientras que, por el lado contrario, están ignorando el hecho de que tal Protocolo es un bien público mundial, que exige la cooperación de todos los países y Estados Unidos no puede dar la solución solo (puntos 3, 5 y 6). Por otra parte, se descuidó el séptimo punto, pues con el rechazo del presidente George W. Bush a la negociación del Protocolo, "trajo como resultado una reacción exterior de frustración y enojo que socavan el soft power". ${ }^{39}$

En suma, Estados Unidos pudo haber tenido un papel preponderante en el primer acuerdo internacional que intenta frenar los efectos perjudiciales del cambio climático, pero no lo hizo. Aparentemente dejó de lado la opinión negativa que la comunidad internacional pudiera tener. Empero, existen elementos dentro de las acciones de Estados Unidos que parecen decir lo contrario, pues poco tiempo después de entrar en vigor el Protocolo de Kyoto, esa nación fundó la AP6 que, aunque cuenta con la colaboración de un número mucho menor de miembros, no descarta la adhesión de otras naciones. Además, es posible que tanto con las medidas internas como con las de la AP6 (por las similitudes que existen entre ellas) Estados Unidos esté forzando a que el resto de los países avance hacia un acuerdo multilateral más efectivo, pues recordemos que este país considera que el Protocolo es dañino e imperfecto por no obligar a los países no desarrollados a cumplir con los objetivos.

\section{Conclusión}

Ser la principal potencia política le brinda a Estados Unidos ciertos privilegios que no tiene el resto de los países. Es la principal emisora de gases de efecto invernadero y, aun así se dio el lujo de desertar del primer acuerdo que intenta reducir los efectos negativos del cambio climático. Las razones son simples:

1. Aunque en Estados Unidos están conscientes de que la prevención de los desastres ambientales es un asunto preponderante, no está dispuesto a disminuir el ritmo creciente del sistema productivo (con todos los efectos que esto conlleva: laboral, financiero, comercial y del consumo), especialmente cuando ve en la tecnología una opción más atrayente, y cuando puede delegar el grueso de la responsabilidad a la iniciativa privada.

2. Desde un principio, el gobierno de Estados Unidos vio en el Protocolo un acuerdo imperfecto y dañino, pues eximía a los países en vías de desarrollo del compromiso obligatorio. Por tanto, fue considerado como un acuerdo que atentaba contra los intereses esenciales de la estabilidad de la nación estadounidense.

3. Pese a la incertidumbre en la arena internacional en la era de la información, donde se requiere reafirmar el poder y la hegemonía, la Casa Blanca está apostando por las acciones tomadas dentro de su territorio para mitigar los gases de efecto invernadero (con las que, por cierto, se han encargado de difundir la información de lo que realizan por todas partes), y las internacionales, como son las acordadas en el AP6. Así esperan recobrar poco a poco el respeto y la admiración (que aparen- 
temente perdieron cuando desertaron del Protocolo de Kyoto) del resto de las economías del mundo.

4. Evidentemente el territorio y la población estadounidenses también son afectados por los efectos adversos del calentamiento global, y éste es un vivo ejemplo en el ese país no puede solucionar un problema sin la ayuda de los otros países (cooperación), pues se trata de un mal público mundial. No obstante, por considerar imperfecto el Protocolo, optó por tomar sus propias medidas.

Como se puede apreciar, aunque en la actualidad el tema del medio ambiente es un asunto prioritario, las medidas tomadas, tanto en la agenda nacional como en la internacional, son incipientes e irrelevantes, pues se sigue dando prioridad al lado económico antes que al ambiental, aun cuando el primero depende por completo del segundo.

Estados Unidos de alguna manera tiene razón al señalar que el Protocolo es imperfecto, tanto por dejar de lado a las economías no desarrolladas y ser poco ambicioso (disminuir la emisión de gases de efecto invernadero sólo en $5.2 \%$ con respecto a 1990), como por el uso de los mecanismos flexibles (opciones para el país signatario de cumplir con el objetivo sin hacer reajustes males en su economía doméstica); empero, es evidente que pocos países ratificarían el acuerdo si no fuera por estas medidas.

\section{Notas:}

1. Dobriansky, Paula,2005, en: http://usinfo.state.gov/journals/itgic/0605/ijgs/dobriansky. htm

2. Véase Hunter, David; Honey, 2000, p. 120.
3. El Programa 21, un plan de acción mundial para promover el desarrollo sostenible, la Declaración de Río sobre el Medio Ambiente y el Desarrollo, y el Convenio sobre la Diversidad Biológica (http:/ /www.un.org).

4. Entró en vigor el 21 de marzo de 1994.

5. Véase, El Protocolo de Kyoto, en: http://www. appa.es/dch/protocolo_kyoto.htm

6. Véase Devraj Ranjit, 2001, en: http://www. tierramerica.net/2002/1110/articulo.shtml

7. 1) Aplicación conjunta: un país desarrollado invierte en otro país desarrollado, en proyecto de energía limpia. El inversor obtiene certificados para reducir emisiones a un precio menor del que habría obtenido en el ámbito nacional, y el país receptor se beneficia de la inversión y la tecnología. 2) Mecanismo de desarrollo limpio: un país desarrollado invierte en tecnología limpia en un país en vías de desarrollo. El recorte de la contaminación derivado de esta inversión se documenta en un certificado que la compañía puede intercambiar por derecho de emisión del país de origen. 3) Comercio de emisiones (mercado similar al de los futuros): los países que emitan por debajo del límite impuesto por el Protocolo pueden vender sus excedentes de derechos de emisión a que países que lo excedan.

8. Alemania, Australia, Austria, Bélgica, Checoslovaquia, Dinamarca, Bielorrusia, Bulgaria, Canadá, Checoslovaquia, Dinamarca, La Comunidad Económica Europea, España, Estados Unidos, Estonia, Federación Rusa, Finlandia. Francia, Grecia, Holanda, Hungría, Irlanda, Islandia, Italia, Japón, Letonia, Lituania, Luxemburgo, Noruega, Nueva Zelanda, Polonia, Portugal, Reino Unido, Rumania, Suecia, Suiza, Turquía y Ucrania.

9. Ídem, en: http://www.tierramerica. net/2002/1110/articulo.shtml

10. Véase Nye, Joseph, 2002.

11. Véase Kakuchi, Suvendrini, 2001, en: http:// www.tierramerica.net/2001/0415/noticias4. shtml

12. Véase Kovaciv, 2004, en: http://www.voltairenet.org/article123180.html

13. Véase Samuelson, Nordhaus, 2002, 26-27.

14. Véase Hussen Ahmed, 2004, 3-4.

15. Ídem, 2004:3

16. Véase Field Barry, Field Martha, 2003, pp. $27-$ 28.

17. Ídem, 2003: 15 .

18. Ídem, 2003: 15 .

19. Ídem, 2003: 15-16.

20. Ídem 2003: 129 . 
21. Véase Tuttle, Andrea, Andrasko Kenneth, 2005, en: http://www.fao.org/docrep/009/a0413s11. htm

22. Idem, pp. 1-2.

23. La AP6 está formada por Estados Unidos, Australia, Japón, Corea del Sur, China e India.

24. Véase Consumer.es, en: http://www. consumer.es/web/es/medio_ambiente/2006/01/09/148397.php?print=true

25. Véase Hunter, David, Honey, Martha, 2000: 120-121.

26. Véase Mearsheimer, John, 2001: 29.

27. Véase Wohlforth, William, 1999: 7.

28. Véase Mearsheimer, John, 1990: 5-8.

29. Un país puede obtener los resultados que quiere en la política mundial porque otros países deciden seguirlo porque admiran sus valores, quieren seguir su ejemplo y aspiran a tener sus niveles de prosperidad y apertura (Nye, Jr., Joseph, 2002:8).

30. El poder militar y el económico pueden inducir a otros a cambiar su postura (Nye, Jr., Joseph, 2002:8).

31. Ídem, pp. 30-31.

32. Mearsheimer, John, 2001:31.

33. Nye, Jr. Joseph, 2003: 143.

34. Ídem, 2003:143.

35. Ídem, 2003:143.

36. Ídem, 2003:143-144.

37. Ídem, 2003: 157-158.

38. Ídem, 2003:159-162.

39. Ídem, 2003:156.

\section{Bibliografía}

El protocolo de Kyoto, en: http://www.appa.es/dch/ protocolo_kyoto.htm

Devraj Raniit, Kyoto y sus desertores, PNUD y PNUMA, 2001, en: http://www.tierramerica.net/2002/1110/articulo.shtml
Dobriansky, P. 2005. "El medio ambiente metas compartidas y misión común", eJournal USA, en: http://usinfo.state.gov/journals/itgic/0605/iigs/ dobriansky.htm

Consumer.es, La Alianza Asia-pacífico pretende discutir el próximo miércoles una alternativa al Protocolo de Kyoto, en: http://www.consumer.es/ web/es/medio_ambiente/2006/01/09/148397. php?print=true

Field B., Field M. 2003. Economía ambiental, $3^{a}$ ed., McGraw Hill. España, pp. 27-28.

Hunter, D., Honey, M. 2000. Global Focus, U.S. FOREIGN POLICY at the TURN of the MILLENNIUM, MacMillan Press, EU, p. 120.

Hussen A. 2001. Principles of Environmental Economics, $2^{\circ}$ ed., Routledge. Nueva York.

Kakuchi, S. 2001. Retiro de EU coloca a Japón en dilema, PNUD y PNUMA, en: http://www.tierramerica. net/2001/0415/noticias4.shtml

Kegley Ch., Wittkopf, E. 1997. World politics, sixth edition, St. Martin Press, Inc, EU.

Kovaciv F. 2004. Estados Unidos contra el mundo, Voltaire, en: http://www.voltairenet.org/article123180.html

Mearsheimer, J. 2001. The tragedy of Great Power Politic, w.w. Norton \& Company EU, p. 29.

Mearsheimer, J. 1990. "Back to the Future Instability in Europe After the Cold War", International Security, Vol. 5, núm. 1, verano, EU. pp.. 5-8.

Nye, Jr. J. 2002. The Paradox of American Power, Why the World's only superpower can't go it alone, Oxford University Press, EU.

Samuelson, N. 2002. Economía, $17^{\circ}$ ed., Mc Graw Hill. España, pp.: 26-27.

Tuttle, A., Andrasko, K. 2005., "Registros de datos e investigación: mitigación del cambio climático y silvicultura en los Estados Unidos", Unasylva, Vol.56, núm. 222, FAO, en: http://www.fao.org/ docrep/009/a0413s $17 . \mathrm{htm}$

Wohlforth W. 1999. "The Stability of a Unipolar World" International Security, Vol. 24, núm. 1, verano EU, p.7. 